JKEP

Vol 5, No 1, Mei 2020

ISSN: 2354-6042 (Print)

ISSN : 2354-6050 (Online)

\title{
Penggunaan Vein Viewer Oleh Perawat Dalam Melakukan Tindakan Venipuncture Pada Pasien Anak
}

\author{
Yersi Ahzani, La Ode Abdul Rahman \\ Universitas Indonesia \\ Email: yersiahzani@gmail.com
}

\author{
Artikel history \\ Dikirim, Dec $3^{\text {th }}, 2019$ \\ Ditinjau, April 26 ${ }^{\text {th }}, 2020$ \\ Diterima, May $6^{\text {th }}, 2020$
}

\begin{abstract}
As the development of technology either vein viewer continues to develop. The use of vein viewers in hospitals helps medical personnel especially nurses to perform venipuncture. Aim of this literature review is to identify the use of vein viewers by nurses to performing venipuncture in children. This literature review uses the Sciendirect, ProQuess, Google Scholar, and IEEE Xplore databases to find journal articles that are relevant to the 20152019 limits using several keywords. Result of analyzed and obtained 5 journal which related with topic of literature review about vein viewer have advantage to process of venipuncture in children. Based on these results, the authors suggest to use of vein viewers in all rooms in the hospital to perform venipuncture measures in children, and suggest conducting research for further development related to existing vein viewer devices.
\end{abstract}

Keyword: Vein Viewer, Children, Venipuncture.

\begin{abstract}
ABSTRAK
Seiring berkembangnya teknologi saat ini, teknologi vein viewer juga terus berkembang. Penggunaan vien viewer di rumah sakit membantu tenaga medis khususnya perawat dalam melakukan tindakan venipuncture. Telaah literatur ini bertujuan untuk mengidentifikasi penggunaan vein viewer oleh perawat dalam melakukan tindakan venipuncture pada anak di rumah sakit. Literature review ini menggunakan database Sciendirect, ProQuess, Google Scholar, dan IEEE Xplore untuk mencari artikel jurnal yang relevan dengan batasan tahun 2015-2019 menggunakan beberapa kata kunci. Ditemukan 5 artikel jurnal yang kemudian dianalisis dan diperoleh hasil bahwa sebagian besar artikel jurnal mengatakan penggunaan vein viewer bermanfaat dalam proses tindakan venipuncture pada anak. Berdasarkan hasil tersebut penulis menyarankan penggunaan vein viewer di semua ruangan di rumah sakit yang melakukan tindakan venipuncture pada anak, serta menyarankan untuk dilakukannya penelitian untuk pengembangan lebih lanjut alat vein viewer yang sudah ada.

Kata Kunci: Penampil Vena, Anak, Penusukan vena.
\end{abstract}




\section{PENDAHULUAN}

Vein viewer adalah alat untuk melihat vena dengan lebih jelas menggunakan kamera infra merah yang dapat memproyeksikan gambar secara real time pada kulit (Conversano, 2018). Seiring dengan perkembangan teknologi saat ini vein viewer terus dikembangkan dalam berbagai bentuk dan rentang harga yang bervariasi agar memudahkan pengguanaannya dan terjangkau bagi konsumennya (Pan, 2019). Penggunaan vien viewer di tatanan layanan rumah sakit membantu tenaga medis khusus nya perawat dalam melakukan tindakan yang berhubungan dengan venipuncture (Gopalakrishnan, 2019).

Tindakan venipuncture pada pasien meliputi pengambilan sampel darah vena, injeksi obat, atau pemasangan akses intravena (Twibell, 2019). Venipuncture merupakan tindakan yang sering dilakukan di tatanan pelayanan rumah sakit, diperkirakan bahwa $80 \%$ pasien anak yang dirawat dirumah sakit mendapatkan tindakan venipuncture (Lucas, 2018). Venipuncture adalah pengalaman yang menegangkan dan menyakitkan bagi anak, dimana dalam proses pelaksanaannya diperkirakan bahwa lebih dari satu kali percobaan yang dibutuhkan pada 1/3 anak untuk mencapai keberhasilan tindakan ini (Conversano, 2018). Hal ini dikarenakan venipuncture membutuhkan penilaian lokasi vena yang tepat untuk dapat melakukan tindakan dengan tingkat keberhasilan satu kali percobaan (Schults, 2019). Vein viewer membantu mendeteksi pembuluh darah vena yang pada sebagian pasien sulit dilihat dengan jelas tanpa alat, sehingga diharapkan dapat meminimalkan kesalahan dan mencegah nyeri atau injuri (Chandra, 2017). Ketersediaan berbagai varian dari vien viewer dengan rentang harga yang bervariasi akan sangat memungkinkan daya beli rumah sakit terhadap alat vien viewer ini dan meningkatkan jumlah perawat yang dapat menggunakannya (Li, Kime, \& Smith, 2018).

\section{METODE}

Metode penelitian ini adalah literature review dengan strategi pencarian artikel jurnal berbahasa Inggris yang relevan dengan topik menggunakan database Sciendirect, ProQuess, Google Scholar, dan IEEE Xplore. Tahun terbit atrikel jurnal dibatasi 2015-2019 dengan kata kunci (vein finder or vein viewer), (vein viewer or children), dan (vein viewer and venifuncture). Dari hasil pencarian artikel jurnal ditemukan 5 artikel jurnal yang sesuai dengan topik. 


\section{HASIL DAN PEMBAHASAN}

Berdasarkan pada 5 artikel jurnal yang telah disesuaikan dengan topik, didapatkan bahwa secara umum pengguna vien viewer merasakan bahwa alat ini dapat membantu dalam proses tindakan yang melibatkan venipuncture pada pasien anak dengan meningkatkan tingkat keberhasilan tindakan pertama, akan tetapi menurut hasil penelitian yang dilakukan oleh Rothbart (2015) menunjukkan bahwa vein viewer tidak memiliki hasil yang signifikan dalam pengurangan waktu dan kemungkinan keberhasilan tindakan venipuncture pada anak. Perbedaan hasil pada artikel jurnal yang ditelaah dipengaruhi oleh berbagai faktor seperti perbedaan yang ada pada karateristik responden yang menjadi sampel dalam penelitian.

Tabel 1.1 Penggunaan Vein Viewer Pada Tindakan Venipuncture Pasien Anak di beberapa negara (United States of America, German, Italy) dalam rentang tahun 2015-2018.

\begin{tabular}{|c|c|c|c|c|c|}
\hline No & Penulis dan Tahun & Sampel & Metode & Random & Hasil \\
\hline 1. & $\begin{array}{l}\text { Mcneely, } \\
\text { L, Heidi., Jodi, } \\
\text { M, Thrasher., } \\
\text { Theresa, L, } \\
\text { Ream., Tiffany, J, } \\
\text { C., \& } \\
\text { Dziadkowiec., O. } \\
\text { (2018). }\end{array}$ & $\begin{array}{l}40 \\
\text { perawat }\end{array}$ & Experiment & $\mathrm{Ya}$ & $\begin{array}{l}\text { Mayoritas responden } \\
\text { merasa perlu } \\
\text { menggunakan vein } \\
\text { viewer untuk } \\
\text { meningkatkan } \\
\text { kemampuan } \\
\text { pemasangan kateter } \\
\text { intravena pada pasien } \\
\text { anak. }\end{array}$ \\
\hline 2. & $\cdot$ & $\begin{array}{l}90 \\
\text { perawat }\end{array}$ & Experiment & $\mathrm{Ya}$ & $\begin{array}{l}\text { Penggunaan vein } \\
\text { visualization pada } \\
\text { intervensi yang } \\
\text { dilakukan perawat anak } \\
\text { menunjukkan bahwa } \\
\text { penggunaan vein } \\
\text { visualization memiliki } \\
\text { manfaat dalam proses } \\
\text { pelaksanaan tindakan } \\
\text { short peripheral } \\
\text { catheter (SPC) } \\
\text { insertion. }\end{array}$ \\
\hline
\end{tabular}




\begin{tabular}{|c|c|c|c|c|c|}
\hline 3. & $\begin{array}{l}\text { Rothbart, A., Yu, } \\
\text { P., Lobeck, L. M., } \\
\text { Spies, Claudia, D., } \\
\text { \& Wernecke, K. } \\
\text { D. (2015). }\end{array}$ & $\begin{array}{l}238 \\
\text { pasien }\end{array}$ & Experiment & Tidak & $\begin{array}{l}\text { Penggunaan vein } \\
\text { viewer tidak dapat } \\
\text { mengurangi waktu } \\
\text { maupun jumlah upaya } \\
\text { dalam melakukan } \\
\text { tindakan akses vena } \\
\text { yang berhasil. }\end{array}$ \\
\hline 4. & $\begin{array}{l}\text { Conversano, E., } \\
\text { Cozzi, G., Pavan, } \\
\text { M., \& Minute, } \\
\text { Marta, (et al). } \\
\text { (2018). }\end{array}$ & $\begin{array}{l}115 \\
\text { pasien }\end{array}$ & Experiment & $\mathrm{Ya}$ & $\begin{array}{l}\text { Penggunaan vein } \\
\text { viewer tidak } \\
\text { mempengaruhi waktu } \\
\text { yang dibutuhkan untuk } \\
\text { melakukan tindakan } \\
\text { venipuncture pada anak } \\
\text { dan tidak } \\
\text { mempengaruhi } \\
\text { keberhasilan tindakan } \\
\text { pertama. }\end{array}$ \\
\hline
\end{tabular}

5. Barreras, J., \& 7896 Experiment Tidak Penggunaan vein Chang, Todd, $\mathrm{P}$. pasien viewer signifikan meningkatkan tingkat keberhasilan akses intravena pada anak.

Vein viewer merupakan alat yang digunakan untuk membantu memvisualisasikan vena agar dapat lebih jelas terlihat (Conversano, 2018). Alat ini diharapakan dapat membantu berbagai tindakan yang diperlukan dalam mengakses vena. Sebagai contoh pada tindakan venipuncture. Tindakan akses vena vaskular yang termasuk dalam tindakan veinpuncture merupakan prosedur yang paling sering dilakukan pada pasien di tatanan layanan rumah sakit (Gerceker, 2018). Upaya pertama insersi pada pasien menunjukkan sering mengalami kegegalan hingga mencapai 50\% dan membutuhkan upaya insersi berulang (Schults, 2019). Tindakan venipuncture berulang juga dapat menimbulkan komplikasi (Tsukuda, 2016).

Selain itu pada pasien anak dapat menyebabkan trauma tersendiri bagi anak, oleh karena itu perawat harus mampu meminimalkan trauma pada anak saat melakukan tindakan venipuncture (Vibhavari, 2019). Permasalahan yang kemudian muncul adalah ketidakseragaman 
kemampuan masing- masing perawat dalam melakukan tindakan venipuncture ini (Schults, 2019). Ketidakberhasilan tindakan seringkali dikarenakan tidak tepatnya penilaian lokasi vena saat ingin melakukan tindakan venipuncture sehingga sulit mendapat keberhasilan hanya dengan satu kali percobaan. Namun seiring dengan perkembangan teknologi maka dikembangkanlah alat untuk membantu ketepatan penilaian lokasi vena dikenal sebagai vein viewer.

Hasil telaah jurnal yang telah dilakukan pada tabel 1.1 menunjukkan bahwa sebagin besar penelitian mendapatkan hasil yang menunjukkan signifikansi manfaat vein viewer untuk membantu proses tindakan venipuncture pada pasien anak (Barreras, 2017). Berdasarkan hasil telaah ini penulis merekomendasikan alat vein viewer untuk dapat digunakan di semua ruangan di rumah sakit yang melakukan tindakan venipuncture pada anak agar dapat memfasilitasi perawat untuk melakukan tindakan dengan tepat dan efektif serta tidak menyebabkan trauma pada anak akibat penusukan berulang.

\section{SIMPULAN}

Vein viewer sebagai teknologi untuk memvisualisasikan pembuluh darah vena pada pasien anak dianggap mampu menjadi alat yang efektif untuk membantu proses penatalaksanaan tindakan venipuncture pada anak. Namun, pada hasil telaah artikel jurnal yang dilakukan ditemukan variasi hasil penelitian terkait penggunaan vein viewer pada tindakan venipuncture pada anak. Meskipun lebih banyak jurnal yang mengatakan manfaat vein viewer, terdapat juga jurnal yang mengungkapkan bahwa penggunaan vein viewer tidaklah efektif.

Diantaranya adalah jurnal yang ditulis oleh Rothbart (2015) dan yang ditulis oleh Conversano (2018). Kedua hasil yang berbeda dipengaruhi oleh berbagai faktor yang menyebabkan tidak konsistennya hasil masing-masing jurnal. Nyatanya akses vaskular pada pasien anak-anak memang menjadi tantangan tersendiri bagi perawat, bahkan dengan sumber daya teknologi yang tersedia saat ini seperti dengan menggunakan vein viewer masih belum dapat sepenuhnya efektif . 


\section{UCAPAN TERIMA KASIH}

Terima kasih kepada semua pihak yang telah berperan serta dan berkontribusi dalam penelitian ini.

\section{DAFTAR RUJUKAN}

Barreras, J., \& Chang, Todd, P. (2017). Using a Near Infrared Device to Improve. Journal of Vascular Access, 22(2),75-

80.https://doi.org/10.1016/j.java.2016 .2 .005

Chandra, F., Wahyudianto, A., Yasin, M. (2017). Design of vein finder with multi tuning wavelength using RGB LED Design of vein finder with multi tuning wavelength using RGB. Journal of Physics.

Conversano, E., Cozzi, G., Pavan, M., \& Minute, Marta, (et al). (2018). Impact of near infrared light in pediatric blood drawing Centre on rate of first attempt success and time of procedure. 1-5.

Fern, R., \& Armada, M. (2017). Multisensory System for the Detection and Localization of Peripheral Subcutaneous

Lucas, Mariana, S. B., Fernanda, G., Bonfi, T., Severino, K. G., Cintra, G., Almeida, D. F., Insper. (2018). Application program to prepare child / family for venipuncture: experience report. 71(3), 1474- 1479.

Mcneely, L, Heidi., Jodi, M, Thrasher., Theresa, L, Ream., Tiffany, J, C., \& Dziadkowiec., O. (2018).Utilization of a biomedical device (Vein Viewer $R)$ to assist with peripheral intravenous catheter (PIV) insertion for pediatric nurses. (December 2017), 1-8. https://doi.org/10.1111/jspn.12208
Gerceker, G, O., Kahraman, A., Yardimci, F., Bilsin, E., Binay, S., Osdemir, C, N, H., Krakul, A., Zengin, et al. (2018). Infiltration and extravasation in pediatric patients: A prevalence study in a children, s. https://doi.org/10.1177/11297298177 $\underline{47532}$

Gopalakrishnan, S., Abhinaav, R., Sapthasri, A, R., Anusha, V., Nivetha, S. (2019). Near-Infrared Based RealTime Peripheral Superficies Venous Imaging Solution for Difficult Venous Access. (3), 6416-6425. https://doi.org/10.35940/ijrte.C5702.0 $\underline{98319}$

Kanipe, W., Shobe, K., Li, Y., Kime, M., \& Smith, Miller, Cheryl, A. (2018). Evaluating the Efficacy and Use of Vein Visualization Equipment Among Clinical Nurses in an Intermediate Care Environment. 27599(August). https://doi.org/10.109

Pan, Cheng, T., Francisco, Mark, D., Yen, Chung, K., \& Wang, Shao, Y. (2019). Vein Pattern Locating Technology for Cannulation: A Review of the LowCost Vein Finder Prototypes. https://doi.org/10.3390/s19163573

Vibhavari, M, Naik., S, Shyam, Prasad, Mantha., Basanth. Kumar, R. (2019). Vascular access in children. (59). https://doi.org/10.4103/ija.IJA 
Rothbart, A., Yu, P., Lobeck, L. M., Spies, Claudia, D., \& Wernecke, K. D. (2015). Peripheral intravenous cannulation with support of infrared laser vein viewing system in a pre operation setting in pediatric patients. BMC Research Notes, 1-7. https://doi.org/10.1186/s1310401514 $31-2$

Schults, J., Rickard, C., \& Kleidon, T. (2019). Difficult Peripheral Venous Access in Children: An International Survey and Critical Appraisal of Assessment Tools and Escalation Pathways.537-546. https://doi.org/10.1111/jnu.12505
Tsukuda, Y., Funakoshi, T., Nasuhara, Y., Nagano, Y., Shimizu, C., Iwasaki, N. (2016). Venipuncture Nerve Injuries in the Upper Extremity From. 00(00), $1-3$.

Twibell, R, K., Hofstetter, P., Siela, D., Brown, D., Jones, M, H. (2019). A Comparative Study of Blood Sampling From Venipuncture and Short Peripheral Catheters in Pediatric Inpatients. (5), 237-247. https://doi.org/10.1097/NAN.000000 0000000338 